\title{
Transformative Images, Temporality and Infra- structures of Feeling: An Interview with Rebecca Coleman
}

FRANCIEN BROEKHUIZEN, Coventry University

SIMON DAWES, Université Paul Valéry, Montpellier

DANAI MIKELLI, Coventry University

POPPY WILDE, Coventry University

\begin{abstract}
In this follow-up interview to her keynote lecture at the MeCCSA-PGN 2015 Conference in Coventry, Rebecca Coleman discusses the affective relations between bodies, images and environments. Coleman offers an overview of her work on images and the body, as well as her interest in theorising the present and the future, and explains her engagement with feminism, new materialism and Deleuze, in particular. To understand how bodies 'become', she argues for the need to understand both process, transformation and change, and what stays, sticks or gets stopped.
\end{abstract}

\section{KEY WORDS}

Affect; Becoming; Bodies; Feelings; Feminism; Future; Images; Present 


\section{Linearity $\leftrightarrow \rightarrow$ Dispersion}

THE EDITORS: In the keynote you delivered at the MeCCSA PGN Conference you explore how the transformative body is not neutral but requires some bodies more than others to transform; for example, classed bodies, gendered bodies etc. In popular media this understanding of transformation is rooted in a linear understanding of becoming, where the future is more closed, drawing us to these futures affectively. Grosz, who you cite in your writings, argues that when we think about becoming and temporality as more complicated, dispersed and entangled, thinking about the future becomes more open-ended. Do you think that this different notion of temporal becomings also allows us to rethink power in relation to the becoming of classed, gendered and racialized bodies? Would this help to provide space for more creativity in the way we think and theorize these bodily becomings?

REBECCA COLEMAN: I think this question gets to the heart of the problem of becoming: that is, how to take seriously and understand both process, transformation, change and what stays, sticks or gets stopped or blocked. If bodies are becomings, do all bodies become in the same ways? Is becoming open to all bodies in the same ways? These are questions I've explored in my research in order to think about becoming and power from a feminist perspective. I'm not sure I could have articulated these thoughts in the same ways whilst I was writing them, but with some distance I might explain them in these terms. In The Becoming of Bodies: Girls, Images, Experience, I wanted to hold on to many of the arguments made in feminist research on visual culture about representations of women, the male gaze etc, and at the same time I was interested in thinking through how the open-ended sense of becoming (taken up from Deleuze and feminist-Deleuzian theorists such as Grosz) might work in terms of how the girls who participated in the research understood their bodies and images. I think there is a central tension in that book about how feminist researchers might engage and coincide with the becoming of the girls bodies - in terms of creativity, inventiveness, immanence and affect - and how the girls also discussed feeling limited through their relations with images. I tried to argue that it is crucial to attend to becoming and its creativity/novelty, and to how this doesn't necessarily imply that the girls' can become in endlessly open ways. By tracking the relations of affect between bodies and images, I was trying to think through relations of power.

In Transforming Images: Screens, Affect, Futures, I explore the open-endedness of futurity in more detail, again trying to hold on to a central tension; this time between the prevalence and significance of the image of the future as better (across popular culture), and how this image of the better future might be felt in, through and by some bodies in particular. Rather than the future being closed, I think that a theme can be identified in popular culture where the future is promised as open, and as better than before. For example, one of the case studies I explore is the Change4Life healthy eating and exercise campaign, where one of the television adverts says that in the future that will emerge after eating better and moving more, we 'all live [...] happily, not exactly ever after, but more ever after than we had done'. I explore the gendered, classed and racialised experience of the pull of the better future, and argue that mothers and ethnic minorities are especially targeted by this campaign. More broadly, my focus in this book was influenced by feminist theory on promises (eg Ahmed 2010) and cruel optimism (Berlant 2008, 2011), as well as more empirical work on anticipation and pre-emption of the future. I try to maintain an ambivalence about the future, that is, not to see it as necessarily or wholly good or bad, but rather to examine what the prevalence of an image of the better future might do; what some of its affects and effects are. 
THE EDITORS: Feminist thinking and feminist narratives are very much located within a forward moving understanding of temporalities that is rooted in change and progress from past, to present, to future. What do you think a more disrupted notion of temporalities would bring to feminist theories and feminist thinking more broadly? And how do you think this could translate to feminist practice in the everyday life?

REBECCA COLEMAN: These are also questions I've been exploring. I've been interested in how understanding feminist theory in terms of a non-linear temporality seems to be helpful - for example, to challenge ideas about the failure of feminism to be passed on across generations in particular ways (i.e. where young women are sometimes cast as failing feminism because what they consider as feminist practices might be different from previous generations' ideas). Among others, Lisa Adkins' (2004) work on the (non-)reproduction of feminism has been important in my thinking here, and Clare Hemmings' (2011) work on feminist stories is also interesting. I think that understanding feminist theory in terms of nonlinear temporalities would be helpful in disrupting ideas about how feminism either should progress or is failing. It seems to me that feminist theoretical trajectories and everyday practices are more complex than this. For example, certain problems seem to be recurrent in feminist theory; they are returned to, and what Christina Hughes and Celia Lury (2013) call 'turned over', again and again.

On these points, I've also been especially interested recently in how the past, present and future, and the 'old' and 'new' are figured in some of the debates about theoretical turns (such as the affective, new materialist or cultural turns); for example, with some arguing that the turns effectively wipe out past feminist work or cast it as over, and/or position 'the new' in affirmative ways. I've been trying to take up the non-linearity of feminist trajectories to think about debates about turns as illuminating struggles over the directions in which feminist theory is going. If feminist theory doesn't so much develop chronologically as, to paraphrase Judith Roof (1997: 87), repeat, alternate, oscillate and develop multi-directionally, debates over theoretical turns might highlight struggle over how particular issues are returned to and explored. They might also make 'new' and 'old' ideas proximate (or not) around a particular topic. For example, in debates over the theoretical turn to the new materialisms, matter and materiality is defined, understood and approached in different ways. While the new materialist turn might define matter in one way, debates about this turn bring a range of definitions, developed in different intellectual contexts and with different histories, together. In this way, some of the different temporalities of feminist theory are not only or so much moved on from but are brought proximate to each other. I develop this line of thinking in a forthcoming (2016) paper in Australian Feminist Studies, in part as an exercise to try to develop a way of thinking about turns that is capable of attending to difference, that is to how debates are central to feminist theory.

\section{Thinking about the present}

THE EDITORS: You mention that at the moment you are interested in what the present is as the present and how this links to infrastructures of feelings. Though you argue that this seems to be impossible, you are still interested in this. Can you explain your fascination with this theoretical concept a bit more and what do you think it will bring to your work on the becoming of bodies? 
REBECCA COLEMAN: It's difficult - and also interesting and productive - to think about the present because it's so slippery! In some ways, this interest in the present comes from the work I've done on futures, which I've argued is both a not-yet time, and a temporality that is brought into and felt in and as the present (through modes and practices of anticipation and pre-emption, for example). So, I've been interested in the present in this work, in that I've been exploring the future in/as the present, and I'm trying to develop it in more detail. I've also come to think more about the present in terms of ideas about hope and optimism, which I've been thinking about for a while. Some theories of hope and optimism argue that these are affects that defer political action to the future (see for example, Berlant 2011). I'm trying to think about what hope might be/how hope might operate, if the future is in the present. I've looked at this in terms of austerity and what I've called '(hopeful) pessimism' as an austerity mood (forthcoming 2016 in new formations), where I've tried to think through a politics of the present in terms of how austerity draws attention to the present rather than the future. I've also found the work of queer theorist Jose Estaban Muñoz (2009) helpful in that he develops an account of hope as an affective potentiality of the future in the present. I'm currently exploring this in terms of developing interdisciplinary sensory methodologies for researching the future and in what might be a book on how the present is experienced and made through different cultural repertoires - for example, I've been interested in the recent proliferation of mindfulness as a method of being present, and how new media technologies are often seen as distracting attention away from the present. I'm not sure yet if/how it relates to the becoming of bodies work, although the focus on affect, sensation and futurity does come from there.

THE EDITORS: You have explored how digital technology relates to the present, through a constant on-ness and "liveness". Could you elaborate on this and discuss how this could link to the vast archive contemporary media is creating, and how having the past in the present might change our perceptions of past and present?

REBECCA COLEMAN: I've been inspired by recent work in sociology on 'liveness' (eg Back and Puwar 2012) and the 'happening of the social' (eg Lury and Wakeford 2012), some of which highlights the significance of digital media to these sensory experiences (eg Clough et al 2014). In the paper I gave at the MeCCSA PGN conference, I was thinking about the present as live and happening through Raymond Williams' essay on structures of feeling (1977). In that essay, he describes culture and society as 'active' and 'flexible'; a 'temporal present'. He explains this conception of the social and cultural in terms of feeling; as a 'quality'; a 'not yet fully articulated' image or idea that hovers 'at the edge of semantic availability' (1977: 132). This is such a great way of describing the social and cultural I think, that ties in with this emphasis on liveness and happening, and with the work on affect that I've been thinking through over the past few years. The paper was a starting point really, and came out of discussions that I've had with Celia Lury (Warwick), Liz Moor (Goldsmiths) and Carolin Gerlitz (Amsterdam). The idea of being 'always on' links to the work on liveness and happening - and also to my own experiences of contemporary media; its instantaneity, connectivity, and always-on-ness, and the checking and alertness that this might provoke.

I think you're right to point to how contemporary media is creating a vast and 'always available' archive that can potentially change our perceptions and relations with time; I wouldn't know what else to say about this at the moment though. 
THE EDITORS: You discuss the notion of speed in relation to data and data analysis that has become possible in contemporary digital societies. The notion of speed in new societies is not new, but was also for example very salient at the beginning of industrialised societies. During industrialisation this speed has created differences between social classes based on their abilities to keep up. To what extent do you think that the speed of digital cultures and data has an influence on the (re)-creation of difference and power structures in contemporary societies?

REBECCA COLEMAN: This is a productive question. There would be an interesting project to do on examining how different media work through different speeds and slownesses. The example of speed I gave was of the production and analysis of some big data; but I think it would be important to consider whether all digital media operate in the same way, with the same rhythms etc. These are some of the things that I've been talking about with Celia Lury, Liz Moor and Carolin Gerlitz - how different media (analogue and digital) orient and frame time differently. There's also been some empirical work on, for example, sustainability, some communities' embrace of 'slow time' (see for example Michelle Bastian's project on Sustaining Time) as a means to challenge, resist or opt-out of speeded up capitalism, and on how 'time poverty' acts as a new form of difference and inequality.

\section{Aspiration}

THE EDITORS: You discuss "anticipation as an affective state, not just a reaction but a way of orienting oneself" as a temporal orientation to the future "as if the future is what matters most" - do you think that there is a comparable state, such as nostalgia, which provides temporal orientation to the past, and how do you think this compares in its affective capacity?

REBECCA COLEMAN: Yes, this is a quote from Vincanne Adams, Michelle Murphy and Adele E. Clarke's work on anticipation (2009). I think there's a lot to be said for how the past is in the present, and nostalgia would be a powerful way in which that occurs and is felt and lived out. I think it's particularly interesting to consider how nostalgia works in the context of austerity. For example, Rebecca Bramall (2013) analyses austerity in terms of popular culture - the 'keep calm and carry on' phenomenon and the 'austerity chic' aesthetic in how homes and cool cafes, restaurants and shops are decorated (see for instance how Farrow and Ball advertising campaigns from 2011 and 2012 were described by the press). It's also there in right-wing discourses about immigration, for example, where a nostalgia about a nation that never really existed becomes a way to explain and justify contemporary policies about refugees and the European Union. Brian Massumi (among others) has written about how preemption of the future works politically through affect rather than evidence or rationalisation; something similar could be said for nostalgia in these cases.

THE EDITORS: Your work on transformation and a temporal orientation to the future resonates with Sara Ahmed's work on the promise of happiness; however, Ahmed suggests that the promise of happiness moves us, but will never become true - "happiness might keep its place as a wish by its failure to be given". Can you expand on how this links to your own 
work and explain how transformation moves us as both a potential promise that orients us towards the future, but also as a moment of change and whether it can be "achieved"?

REBECCA COLEMAN: My understanding of transformation comes from my understanding of becoming - so I see transformation as a process that is never complete or finished. In Transforming Images, I explore how this open-endedness operates as a mode of power; the bodies and selves of some feel an imperative for constant transformation, whether that be through consumption, dieting, healthy eating and exercise, attention to dress, etc. These practices suit the logics of capitalism, which requires change and flexibility. In Berlant's terms (2011: 103), it is 'easy and not false' to point this out; what is also crucial, and perhaps more difficult, to explain is how and why people might well be aware that their practices are ultimately unachievable, but nevertheless do them anyway, and moreover, how they experience these practices. I've tried to explore this problem through focusing on how power works affectively, through drawing in some people to the image of the better future. I agree with Ahmed (and Berlant) that the promise of happiness and/or a better future will almost certainly never come true (it's on-going and open-ended, as is becoming). And I'm also interested in how this promise persists, how it persists more strongly for some people rather than others, and how it is experienced by those who attach to or engage with it.

\section{Thinking about bodies}

THE EDITORS: In your work you refer to new materialism and how this can help to understand the becomings of bodies both through a materialist approach while also including a discursive approach. Can you expand a bit further on the combination of these two notions in relation to the becoming of bodies? What does the combination of these two notions bring us and enable us to do?

REBECCA COLEMAN: This questions refers me back to the thinking I've been doing on 'turns', and how to be interested and engaged in a turn (as I am with the affective and new materialist turns) is not necessarily to sideline or drop important feminist work developed in other intellectual and historical contexts. One way I've tried to explore this is how feminists working with ideas developed in the cultural turn (primarily with Foucault's notion of discourse) were grappling with an issue which animates new materialist feminists; namely, 'representation' and the relationships between images and bodies (see for example 'Inventive Feminist Theory', in Women: A Cultural Review (2014)). So these relations remain key across different turns, and perhaps different theoretical positions circulate around them and illuminate different aspects of them. While I've primarily worked to understand images in terms of their affectivity and materiality, I wouldn't want to lose the more textual or discursive understandings of images; indeed, these unfortunately remain strategically important.

THE EDITORS: Your work is very focused on bodies and on social structures co-producing these bodies, at the same time your recent work shows an interest in a more non-human/posthuman approach. Could you expand on your use of this term in your work, what it means for your work and how it helps in rethinking the becoming of (human) bodies? 
REBECCA COLEMAN: Theories of the new materialisms and affect focus attention not only on human bodies, but also on how human bodies are in environments, ecologies or networks of other bodies. I think in general, ideas about the non-human and post-human have become more prevalent since The Becoming of Bodies book, but this idea has always been central to my understanding of becoming - Deleuze's notions of assemblages and affect both require a thinking through of the relations between humans and non-humans, and his concept of the body is that it is a (temporary) coagulation of parts (or organs). In The Becoming of Bodies, I tried to think through this in terms of the relations between bodies and images - so in some ways, I am trying to understand bodies as assemblages of images, where images have different affective intensities and durations. This was important in terms of how I was attempting to re-work media-effects models of the relations between bodies and images, by arguing that bodies and images aren't separate and mutually exclusive, but that bodies become through their relations with images.

\section{References}

Adams, V., Murphy, M. and Clarke, A. E. (2009) 'Anticipation: technoscience, life,affect, temporality', Subjectivity, 28(1): 246-265.

Adkins, L. (2004) 'Passing on feminism: From consciousness to reflexivity?', European Journal of Women's Studies, 11 (4): 427-444.

Ahmed, S. (2010) The Promise of Happiness, Durham, NC and London: Duke University Press.

Back, L. and Puwar, N. (eds) (2012) Live Methods, Oxford: Blackwell.

Berlant, L. (2006) 'Cruel optimism', Differences: A Journal of Feminist Cultural Studies, 17(3): 20-36. - the 2008 should change to 2006 in response to $Q 1$

Berlant, L. (2011) Cruel Optimism, Durham, NC and London: Duke University Press.

Bramall, R. (2012) The Cultural Politics of Austerity, London, Routledge.

Clough, P. T., Gregory, K, Haber, B and Scannell, R. J. (2014) 'The Datalogical Turn', at: https://www.academia.edu/5986819/The_Datalogical_Turn, last accessed 20th October 2015.

Coleman, R. (2009) The Becoming of Bodies: Girls, Images, Experience, Manchester: Manchester University Press.

Coleman, R. (2012) Transforming Images: Screens, Affect, Futures, London: Routledge.

Coleman, Rebecca (2014) 'Intensive feminist theory: Representation, Materiality and Intensive Time', Women: A Cultural Review, 25(1): pp. 27-45. 
Coleman, R. (forthcoming 2016) 'Notes towards a surfacing of feminist theoretical turns', Australian Feminist Studies.

Coleman, R. (forthcoming 2016) 'Austerity Futures: Debt, Temporality and (Hopeful) Pessimism as an Austerity Mood', Contribution to Special Issue of New Formations on The Future of Austerity: The Cultural Politics of Indebtedness, edited by Rebecca Bramall and Jeremy Gilbert

Hemmings, Clare (2011) Why Stories Matter: The Political Grammar of Feminist Theory, Durham and London: Duke University Press.

Hughes, C. and Lury, C. (2013) 'Re-turning feminist methodologies: from a social to an ecological epistemology', Gender and Education, 25 (6): 786-799.

Lury, C. and Wakeford, N. (2012), 'Introduction: A Perpetual Inventory', in (eds) Inventive Methods: The Happening of the Social, London: Routledge: 1-24.

Massumi, Brian (2005) 'The future birth of the affective fact', Conference Proceedings: Genealogies of Biopolitics, available at: http://browse.reticular.info/text/collected/massumi.pdf, last accessed 14 July 2011.

Muñoz, J. E. (2009) Cruising Utopia: The Then and There of Queer Futurity, New York and London: New York University Press.

Roof, J. (1997) 'Generational Difficulties; or, The Fear of a Barren History', in D. Looser and E.A. Kaplan (eds) Generations: Academic Feminists in Dialogue. Minneapolis and London: University of Minnesota Press, pp. 69-87.

Williams, R. (1977) 'Structures of Feeling', in Marxism and Literature, Oxford: Oxford University Press, pp. 128-135.

Rebecca Coleman is Senior Lecturer in the Sociology Department, Goldsmiths, University of London, where she researches and teaches on sensory sociology; bodies; time, especially presents and futures; inventive methodologies; and social, cultural and feminist theory. She recently led the ESRC Research Seminar Series on Austerity Futures: Imagining and Materialising the Future in an Age of Austerity (2012-14) and is currently working on projects concerned with developing interdisciplinary approaches and methodologies for studying temporality. Recent publications include Transforming Images: Screens, Affect, Futures (2012, Routledge), and Deleuze and Research Methodologies (edited with Jessica Ringrose, 2013, Edinburgh University Press). Forthcoming publications are on surfaces and temporality, austerity, affect and futurity, and on the development of a sociology of the future.

Email: rebecca.coleman@gold.ac.uk 